their employers, as to all the purposes of comfort. There is no reason, save ignorance, why they should not have refreshing baths after their daily toil, and abundant change of comely garments conducive to health. There is no reason, save ignorance, why they should not have abundance of good and well-prepared lood for the body, and access to books of all kinds for the proper culture of the mind. There is no reason, save ignorance, why they should not have access to theatres, and operas, and lectures of all kinds, and picture and sculpture galleries, and museums, far more imposing than any thing the world has yet beheld. There is no reason, save ignorance, why the great body of the working people should not possess, in addition to all that is necessary for the comfortable maintenance of the body, all the pleasures of mental refinement, which are now only within the grasp of the very rich. There is no reason, save ignorance, why the ruling power of the state should not be in their own hands, and all else, save only the excitements of ostentation, and expensive sensuality."

[Tait's Mag.

\title{
II Pin Heading.
}

The process of pin-heading, three establishments for which I visited, is carried on in the following way: A large room is filled with small tables, at each of which sit four children, about thirty or forty together in a room, and certainly of ages lower than I should sup. pose it possible could be employed in any other gainful occupation. The majority of those I saw did not appear to be above seven or eight; and, in fact, the scene, as far as regards the ages of the children, reminded me more of an infant school, than any thing else I had ever witnessed. A sort of frame is fixed before each child, on which is suspended a heavy weight, which is kept in perpetual motion by the child pressing its foot on a treadle beneath the table; and the continual thumping noise of which, close to the infant's ear, seems well calculated to produce the ear-ache, complained of by several witnesses. Each child is in a position continually bent in the form of the letter $C$, its head being about eight inches from the table, and both its hands engaged in taking up the shanks, and putting heads on them, which heads are then tightened by blows from the weight suspended before it. On the whole, the employment of pin-heading seemed to me the most irksome and monotonous, without exception, I had ever witnessed; and knowing the cruelties that are sometimes practised at it, to keep their infants at work, I was not surprised at being told by a manufacturer, that he had been once engaged in the trade, but had left it, owing to the disgust he felt at this part of the business.-Mr. Tuffnell's Report, Factory Commission.

[Lond. Mech. Mag.

\section{Remarks on Flame. By Mr. J. Murray.}

The non-transit of flame through orifices formed in non-radiating and non-conducting materials, I was the first to establish, in dis- 
tinct contradiction to the universally received opinion, and none has ever advanced, so far, a fairer claim. The recent experiments of Dr. C. Williams have also fully corroborated my other views respecting fame, namely, that though it cannot be denied that there are flames which possess intense temperatures, there are other specific flames which exhibit comparatively low grades of temperature. 'Thus, Dr. Williams has shown that there are flames into which the finger may be introduced without suffering; therefore, the assumption that "flame, in all cases, is inflammable or gaseous matter, heated above whiteness," "and that to a degree infinitely above the while heat of solid bodies," is an error of the most palpable description. $\quad[I b$.

\section{List of American Patents which issued in February, 1855.}

58. Straw cutler.-Stephen Ustick, city of Philadelphia,

Feb.

59. Sawing staves. - Hart Pepper, Sonthwick, Mass.

60. Fur cutting machine.-Curtis M. Sampson, city of New York,

61. Thrashing machine.-Joseph Ross, Boundbrook, New Jersey,

62. Clover hulling.

"

66,6

63. Ships' windlass. - Seth Adams, Boston, Mass.

64. Cheese press.-Rufus Porter, Belerica, Mass.

65. Washing machine, $-\Lambda$ mos C. Hanniford, Northfield, New Hampshire,

66. Auger, or bil.-Fzra L'Hommedieu, Saybrook, Conn.

67. Theodolite.-James Eames, Newry, Maine,

68. Horse rake. - Noah Briggs, New Hartford, New York,

69. Corn shcller.-J. II. Taylor and A. J. Cowles, Westfield, N. Y.

70. Plough.-David Ghormles, Wayne, Ohio,

71. Hogs, scalding.--Thomas J. Godman, city of Baltimore,

72. Furnace bake-aven.-Charles E. Russell, city of Philadelphia,

73. Plough.--Nathan Robinson, Sacketts' Harbour, New York,

74. Brad cutter, revolving.-A. B. Woods, and E. Talbot, Jr., Windsor, Conn.

75. Cotton planter.-Michael Bean, Buffaloe, North Carolina,

76. Con sheller.-E. Reed, and A. L. Norcross, Hallowell, Maine,

77. Forge back.-Isaac Sawyer, Hallowell, Maine,

78. Brick striker.-Peleg Sweet, Ashtabula, Ohio,

79. Paper making.-John Ames, Springfield, Mass.

80. Cement for reservoirs, -John C. Johnston, Cattskill, New York,

81. Rolury steam engine.-George M. Alsop, city of Philadelphia,

82. Water proof roofs. -Lyman Garfield, Troy, New York,

83. Ventilation for ships.-James Barron, city of Philadelphia,

84. Percussion lock. - Robert Beale, city of Washington,

85. Mill bush, ring, and bale.-Warren P. Wing, Greenwich, Mass.

86. Plough.-Benjamin Johnston, Hickory Grove, 111 .

87. Percussion lock.-Thomas Duplyn, Dover, Delaware,

88. Scoop shovel.-J. and W. Smith, Williamstown, Mass.

89. Chairs, ESc. on rail.roads.-J. M. Palisse, and S. S. Durfee, Hudson, New York,

90. Cooking strve.-Paul Wing, Grafton, Mass.

91. Culting meat.-John Morris, Derby, Conn.

92. Propellinir wheel-Nehemiah Dodse, city of New York, 25

93. Mortising machine.-Grove Bradley, Auburn, New York, $\quad 25$

94. Potato washing machine.-William Ellis, Waterville, Maine, 25

95. Branding irons.-E. Barns, G. Hills, and J. B. Hawkins, Ashtabula, Ohio, 